\title{
Little Botany: A Mobile Game Utilizing Data Integration to Enhance Plant Science Education
}

\author{
Suphanut Jamonnak and En Cheng \\ Department of Computer Science, College of Arts and Sciences, University of Akron, Akron, OH 44325-4003, USA \\ Correspondence should be addressed to En Cheng; echeng@uakron.edu
}

Received 6 December 2016; Revised 31 January 2017; Accepted 7 February 2017; Published 22 March 2017

Academic Editor: Michela Mortara

Copyright (C) 2017 Suphanut Jamonnak and En Cheng. This is an open access article distributed under the Creative Commons Attribution License, which permits unrestricted use, distribution, and reproduction in any medium, provided the original work is properly cited.

\begin{abstract}
Mobile devices are rapidly becoming the new medium of educational and social life for young people, and hence mobile educational games have become an important mechanism for learning. To help school-aged children learn about the fascinating world of plants, we present a mobile educational game called Little Botany, where players can create their own virtual gardens in any location on earth. One unique feature of Little Botany is that the game is built upon real-world data by leveraging data integration mechanism. The gardens created in Little Botany are augmented with real-world location data and real-time weather data. More specifically, Little Botany is using real-time weather data for the garden location to simulate how the weather affects plants growth. Little Botany players can learn to select what crops to plant, maintain their own garden, watch crops to grow, tend the crops on a daily basis, and harvest them. With this game, users can also learn plant structure and three chemical reactions.
\end{abstract}

\section{Introduction}

School-aged children worldwide are growing up immersed in a media-rich, "always connected" world. New technology has brought with it new tools for learning, and research has shown that the educational potential of mobile games resonates with teachers and students [1]. Game is an important element for healthy child development including learning development. Mobile educational games provide an opportunity for players to learn through simulated environments; these games are not necessarily a distraction from learning; rather they can be an integral part of learning and intellectual development [2-5]. Mobile devices are rapidly becoming the new medium of educational and social life for young people, and hence mobile educational games [6-8] are a key topic for researchers and software developers. It is worth mentioning that the strengths of the mobile platform include its portability, context sensitivity, connectivity, and ubiquity, which make it ideal for educational games in elementary, secondary, university, and lifelong education.

Despite its apparent simplicity, gardening is actually a complex system involving the emergent interaction of multiple parameters. Successful gardeners usually need to juggle highly technical knowledge about a plant's sunlight and shade requirements, water needs, and what plants grow well together when placed near each other in a plot. To help school-aged children learn about the fascinating world of plants, we present a mobile educational game called Little Botany, where players can create their own dream gardens in any location on earth. The principal environmental requirements for plant growth include adequate space for root and canopy development, sufficient light, water, oxygen, carbon dioxide, and mineral elements, and temperature suitable for essential physiological processes [9]. Weather plays a major role in the healthy growth and development of plants. To simulate how the weather affects plants growth, the virtual gardens created in Little Botany are using real-time weather data for the garden location. The game also teaches users how to care for the plants on a daily basis. For instance, an adequate amount of water is essential for plant growth and maintenance of essential plant processes. With this game, users can discover where our food comes from and learn how to tend and harvest crops.

This paper is based upon a previous work [8], but the main contribution with respect to this work can be found in Related Work, Game Design, and Evaluation. The 
TABLE 1: Numbers of installations for five gardening games from Google Play Store.

\begin{tabular}{lc}
\hline Game name & Number of installations \\
\hline Farm Story & $10,000,000-50,000,000$ \\
Inner Garden & $1,000,000-5,000,000$ \\
Flower House & $500,000-1,000,000$ \\
Sweet Garden & $500,000-1,000,000$ \\
Dream Garden & $100,000-500,000$ \\
\hline
\end{tabular}

remainder of this paper is structured as follows: Section 2 presents some related work; Section 3 describes the game design of Little Botany; Section 4 presents the three-layered system architecture of Little Botany; Section 5 describes three service agents, which are backend support for Little Botany; Section 6 illustrates the main functionalities provided by Little Botany; Section 7 presents evaluation results for Little Botany; Section 8 concludes the paper with discussions and future work.

\section{Related Work}

The primary mobile game market consists of Apple Store for iOS devices such as iPhone and iPad and Google Play Store for Android devices such as Samsung Galaxy and Nexus. In this section, we review five mobile gardening games that have been released on Google Play Store, because Google Play Store provides the total user installations for each game. Table 1 summarizes the number of installations for each game, which is useful for identifying the potential of user's interest in gardening games.

Farm Story [10] provides over 150 varieties of delicious fruits, veggies, and beautiful flowers. Farm Story allows players to design and decorate their farms with fences and building. Moreover, Farm Story allows players to have animals such as cows, sheep, and chicken. Players can visit their neighbors and view their friends' garden over social networks.

Inner Garden allows players to design and decorate their own garden [11]. Players can also take a photo of their garden and share it with their friends over social networks. It contains a realistic art in $2 \mathrm{D}$ world, which consists of recognizable plant species for children and adults.

Flower House [12] provides 139 unique flowers and 10 different characters. The game has approximately 500 thousand to 1 million installations. Flower House allows players to decorate unique interior garden with various flowerpots and statuettes. It provides functionality for players to sell their flowers and send them as a gift to their friends over the social network.

Sweet Garden [13] is one of the unique applications that allow players to add flower as a widget over the mobile screen. It creates an interactive flower over mobile user interface in real time. Furthermore, it also generates different characteristics and scenarios of flowers over the mobile interface.

Dream Garden [14] allows players to dress up their gardener's outfit and wear some favorite clothes. Dream
Garden has approximately 100 thousand to 500 thousand installations. Dream Garden also provides gardening techniques. For instance, players will regularly water the plants with a watering can, prune their plants with scissors, trim the grass around the fence, or cut the lawn in the garden.

Our study of these five gardening games on the Google Play Store indicates the popularity of garden-themed games. To help school-aged children learn about the fascinating world of plants, Little Botany [8] attempts to leverage realworld location data and real-time weather data to create a virtual reality garden for users. More specifically, Little Botany is using real-time weather data for the garden location to simulate how weather affects plants growth. Little Botany players can learn to plan their own garden, select what crops to plant, watch crops to grow, tend the crops on a daily basis, and harvest them. With this game, users can also track plant growth and learn plant structure.

\section{Game Design}

3.1. Functionality Design. Storyboard is commonly used to illustrate the ideas and activities of a game. At the early design stage of Little Botany, we followed the strategies for serious game design proposed by the researchers [15-17] to accomplish functionality design for Little Botany. The activities in Figure 1 show the sequential actions performed by a game player. For example, if a player wants to create a garden, he can first select a location and choose a starting date for his garden.

Scenes and modules are used to illustrate the functional components of Little Botany. Figure 2 shows the scenes and modules designed for Little Botany. Virtual garden scene focuses on simulating plants growth in different stages, different locations, and different weather. Moreover, it also plays an important role in teaching players about how to take care of their plants. For instance, players need water and spray pesticide to protect their plants in a garden. Educational scene consists of two different modules, which are plant structures and plant chemical reaction. These two modules focus on teaching players about plant anatomy, photosynthesis, respiration, and transpiration.

3.2. Usability Design. The usability design in Little Botany focuses on user interface (UI) and gestures. Users can play our game by using gestures such as swiping, rotating, scaling, and drag-and-drop. We designed UI to support two mobile operating systems including iOS and Android. We have designed the UI in Little Botany according to the graphical areas of usage in landscape view. The areas over the mobile's UI contain light pink, light blue, and burlywood colors, which can be represented as the reachable areas including easy, normal, and difficult, respectively, in Figure 3.

Figure 4 illustrates the UI layout of Little Botany in landscape view. We started by providing the "home" button on the top-right corner. Players need to stretch their finger in order to reach the "home" button. In contrast, we put "gardening tool" buttons in the center-bottom area of the screen for easier access. 


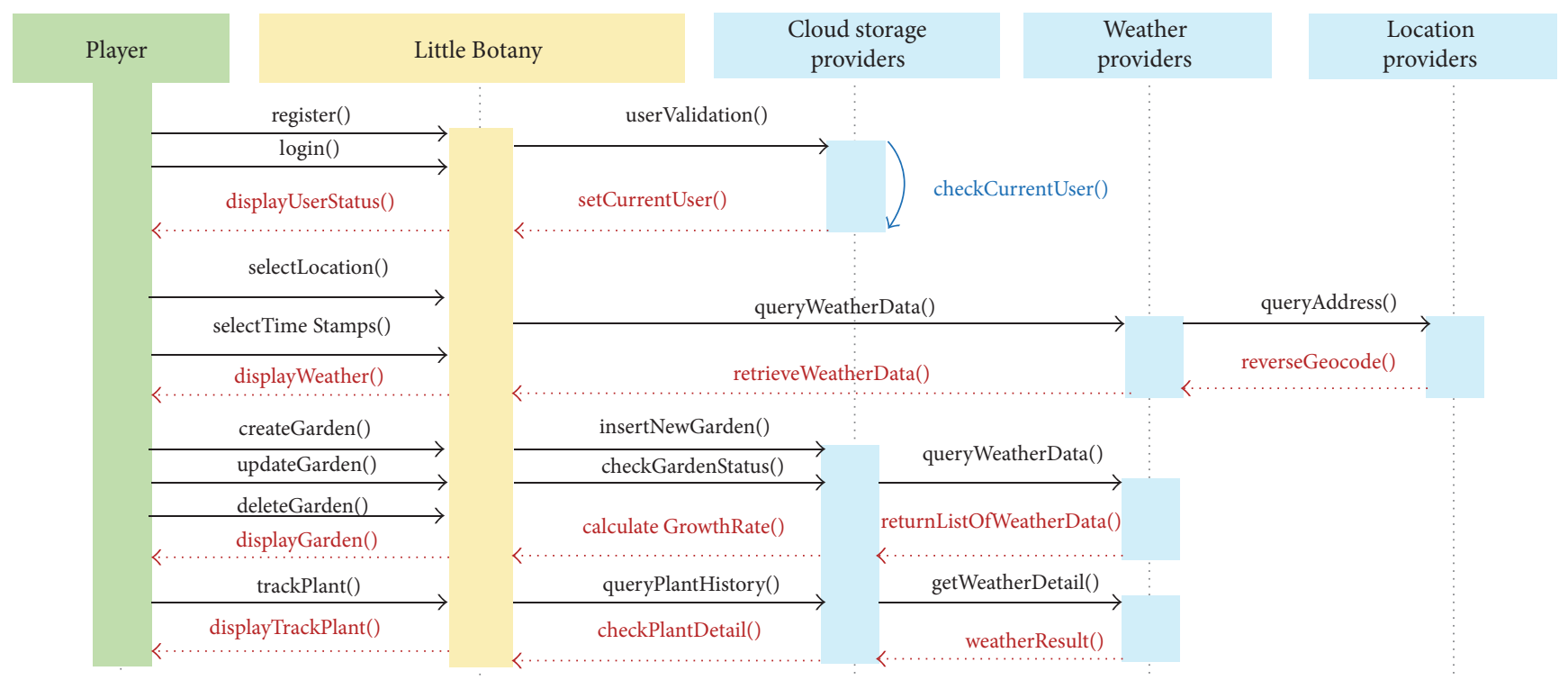

Figure 1: An illustration of player activities in Little Botany.

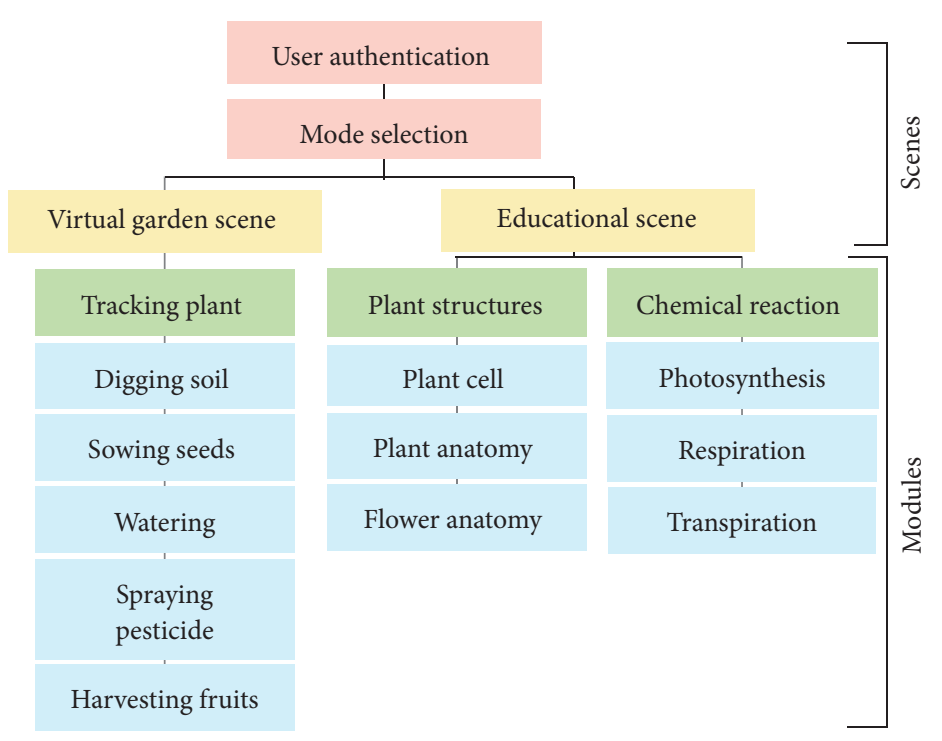

FIGURE 2: Scenes and modules designed for Little Botany.

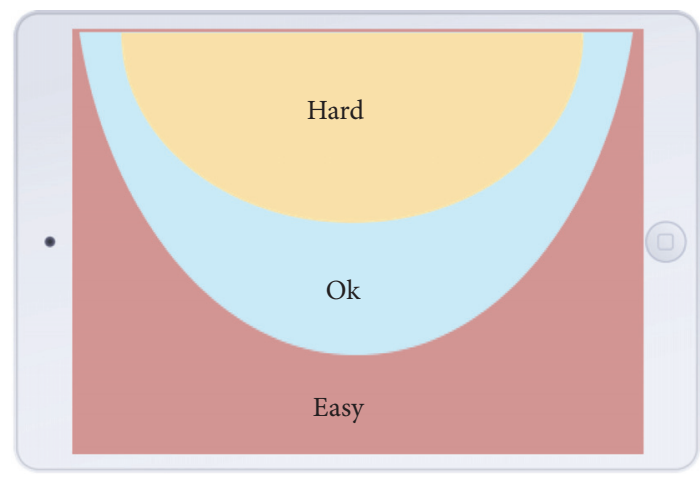

FIGURE 3: Graphical usages of mobile UI in landscape view.

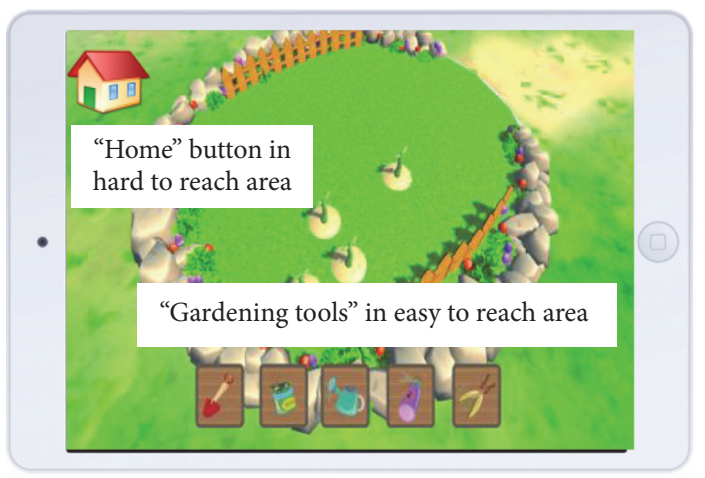

FIgURE 4: Little Botany UI design. 


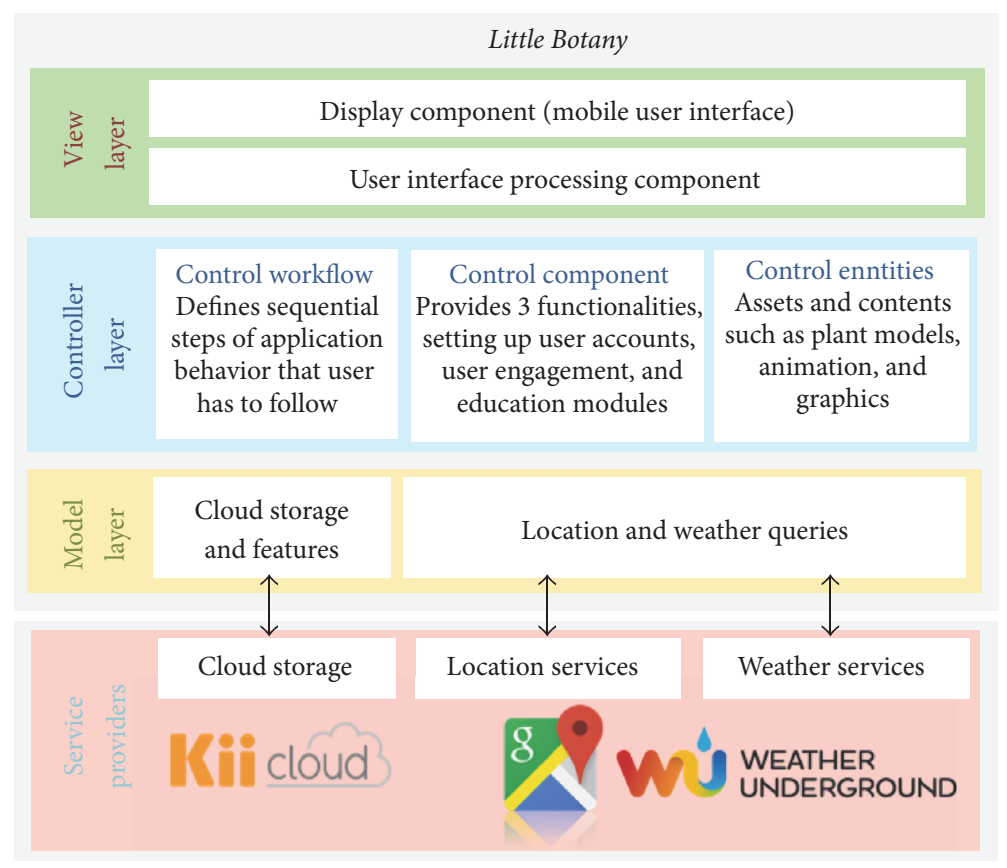

FIGURE 5: The system architecture of Little Botany.

Touch gestures are the combination of finger movements and clicks. In this project, we designed our application to recognize different touch gestures and events such as pointing, panning, zooming, rotating, and swiping. For example, one common gesture is to use one finger in a downward or upward motion to scroll. With the touch functions provided by Unity3D, we provide several gestures that can be used to interact with multitouch devices such as smartphones and tablets.

\section{System Architecture}

The system architecture of Little Botany has three layers including view layer, controller layer, and model layer. The Unity3D game engine [18] is the development framework for Little Botany. We used Unity3D to implement game mechanisms in C\# and JavaScript programming languages. To generate 3D models and assets in our game, we use Autodesk Maya [19], 3D computer graphics software that runs on Windows, OS X, and Linux. Figure 5 illustrates the system architecture of Little Botany.

4.1. View Layer. The view layer contains the components for building user interface and managing user interaction. Unity3D new UI system provides an efficient approach to create UI components, such as buttons, input fields, images, panels, and texts, which are placed and displayed on the top of the game's canvas. Moreover, Unity3D also supports user input from multiple devices. Users can play our game by using gestures such as swiping, rotating, scaling, and dragand-drop.

4.2. Controller Layer. In Little Botany, controller layer has three components: control workflow, control components, and control entities. We explain the roles and responsibilities of each component as follows.

(i) Control Workflow. Users usually take multiple steps to accomplish a task. The steps must be performed in a correct order and orchestrated. For example, users need to select a location and a specific date before creating their garden or users need to follow the gardening steps by digging the soil first before sowing seeds.

(ii) Control Components. Little Botany provides three control components, which are (1) setting up user accounts, (2) user engagement, and (3) education modules:

(1) Setting up user accounts: users are required to set up their accounts before creating gardens

(2) User engagement: the component provides the entertainment content for users. The goal is to motivate users to play the game and learn how to grow plants. In addition, users can simulate plant development and track their plant growth

(3) Education modules: the component contains in-depth knowledge about gardening and plant growth. Users can learn about plant structure and plant growth factors including photosynthesis, respiration, transpiration, light, temperature, and water

(iii) Control Entities. Game objects such as plant models, gardens, images, and colors are drawn under the Unity3D graphic pipeline. Ultimately, Little Botany can have twenty plants for users to choose. Each plant has thirty static models represented as plant development stages. 


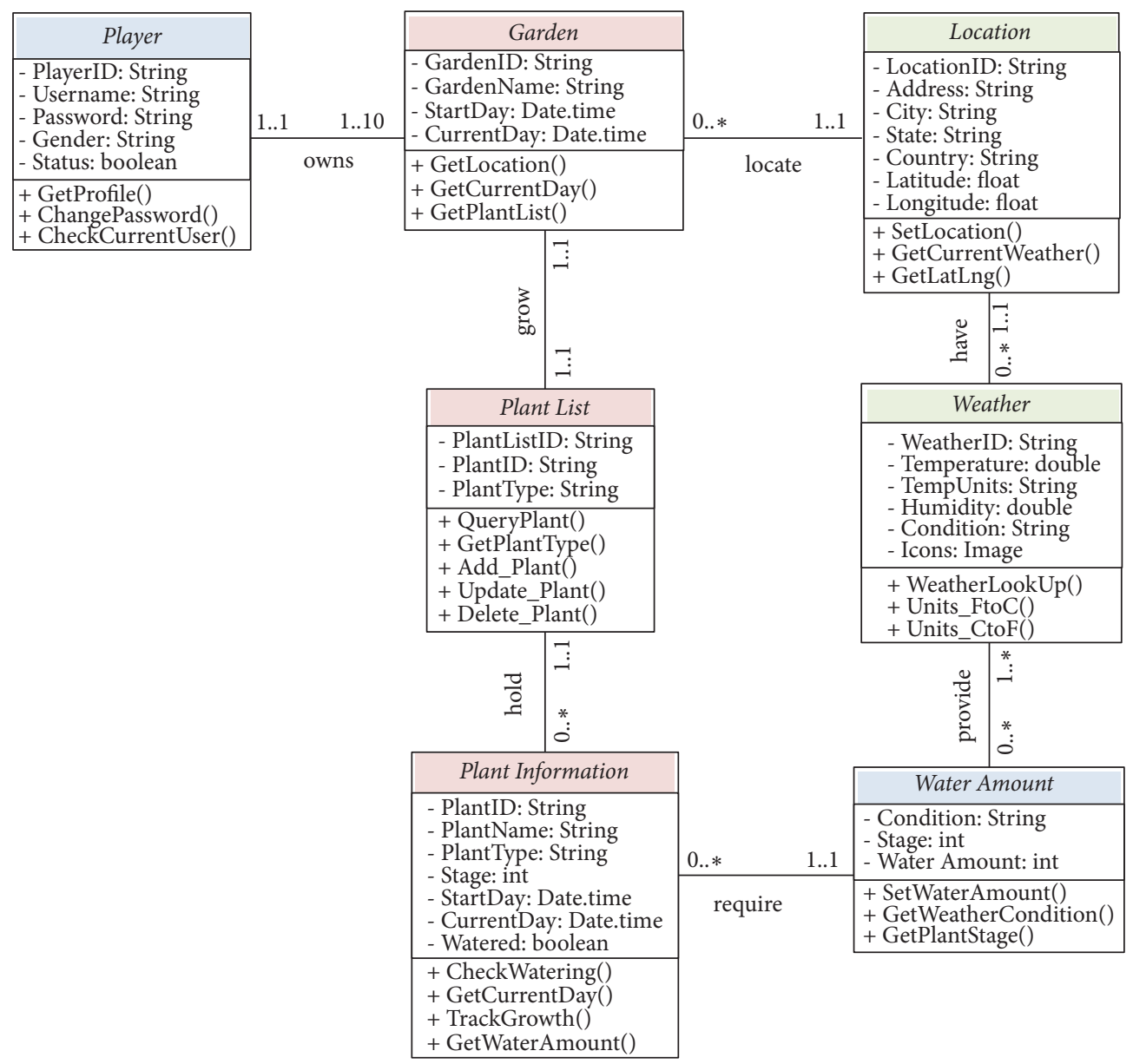

FIGURE 6: Database schema of Little Botany.

4.3. Model Layer. Model layer stores each user's game data in Little Botany. Model layer plays an important role in the three-layer architecture. Controller layer cannot function properly without accurate data provided by model layer. Model layer includes data management and service agent described as follows.

(i) Data Management. This component centralizes the data access functionality, which makes the application easy to configure and maintain. In Little Botany, game data is stored in the cloud storage named "Kii Cloud" [20]. This cloud storage provides us the ability to develop our game application without worrying about server-side implementation and operations.

(ii) Service Agent. Controller layer is built upon multiple external service agents, which provide data for business components' implementation. In this component, we develop the code to manage and communicate with external services. To provide weather and location for a user, we have selected external services including wunderground.com [21] for weather data and Google Maps Geocoding API [22] for location data.

\section{Services}

5.1. Mobile Backend as a Service (MBaaS). MBaaS [23] provides various server-side features such as user authentication, data management, application analytics, and push notification. With MBaaS, we can develop our mobile application without burden by server-side implementation and operations. We considered several MBaaS providers [24]. In the end, we found Kii Cloud [20] provided by Kii Corporation, which can fulfill the requirements for Little Botany.

Using Kii Cloud, We implemented server-side logic and applications for Little Botany. In addition, our application uses Kii Cloud to allow users to store game data on the server or share data among multiple devices. Figure 6 illustrates the schema designed for Little Botany using UML diagram. Kii Cloud lets us manage our server 24 hours a day and 365 days a year. It also enables us to react quickly to the issue and recover our service promptly. Furthermore, Kii Cloud is also enabling us to develop and distribute our application along with their provided Unity SDK.

For developers, Kii Unity SDK is easy to work with in terms of developing server-side logic. This SDK consists of KiiObject, Bucket, User, Scope, and Push Notification. In 
TABLE 2: A sample of weather data.

\begin{tabular}{|c|c|c|c|c|c|c|c|c|c|c|}
\hline Time SGT & $\begin{array}{l}\text { Temperature } \\
(F)\end{array}$ & $\begin{array}{c}\text { Dew point } \\
(F)\end{array}$ & Humidity & $\begin{array}{l}\text { Sea level } \\
\text { pressure }\end{array}$ & $\begin{array}{l}\text { Visibility } \\
\text { (MPH) }\end{array}$ & $\begin{array}{c}\text { Wind } \\
\text { direction }\end{array}$ & $\begin{array}{l}\text { Wind speed } \\
(\mathrm{MPH})\end{array}$ & Events & Conditions & Date UTC \\
\hline $12: 00 \mathrm{AM}$ & 84.2 & 73.4 & 70 & 29.86 & 6.2 & SSE & 6.9 & N/A & $\begin{array}{l}\text { Mostly } \\
\text { cloudy }\end{array}$ & $\begin{array}{c}2014-10- \\
09 \\
16: 00: 00\end{array}$ \\
\hline $12: 30 \mathrm{AM}$ & 84.2 & 73.4 & 70 & 29.86 & 6.2 & SE & 6.9 & N/A & $\begin{array}{l}\text { Mostly } \\
\text { cloudy }\end{array}$ & $\begin{array}{c}2014-10- \\
09 \\
16: 30: 00\end{array}$ \\
\hline 1:00 AM & 84.2 & 75.2 & 74 & 29.86 & 6.2 & SE & 6.9 & N/A & $\begin{array}{l}\text { Mostly } \\
\text { cloudy }\end{array}$ & $\begin{array}{c}2014-10- \\
09 \\
17: 00: 00\end{array}$ \\
\hline 1:30 AM & 82.4 & 75.2 & 79 & 29.86 & 6.2 & SE & 6.9 & N/A & $\begin{array}{l}\text { Mostly } \\
\text { cloudy }\end{array}$ & $\begin{array}{c}\text { 2014-10- } \\
09, \\
\text { 17:30:00 }\end{array}$ \\
\hline 2:00 AM & 83 & 74 & 69 & 29.84 & 9 & SE & 6.9 & N/A & Hazy & $\begin{array}{c}\text { 2014-10- } \\
09, \\
18: 00: 00\end{array}$ \\
\hline
\end{tabular}

Little Botany, we use KiiObject for storing application data. We can store values and string using key-value pair, and these key-value pairs are stored as JSON format. We also use Bucket to organize multiple KiiObjects, which act like a container for KiiObjects.

5.2. Location Services. Little Botany provides users the flexibility to choose any location on earth to start a garden. To provide an easy way for users to choose a location, users can touch a spherical globe designed in Little Botany. With the Unity3D game engine, Little Botany can retrieve usertouched position in 3-dimensional world and convert it to the geographic coordinates with latitude and longitude values. Giving the geographic coordinates as inputs, we need to use web services to retrieve a specific location. In Little Botany, we use Google Maps Geocoding API [22] provided by Google Inc. This API has the capability of converting latitude and longitude values to human-readable address. The returned addresses have four different formats. Given 40.714224 in latitude and 73.961452 in longitude as inputs, we illustrate how Google Maps Geocoding API retrieves a specific location as follows.

Input: Google Maps Geocoding API (40.714224 in Latitude and 73.961452 in Longitude)

http://maps.googleapis.com/maps/api/geocode/json? latlng $=40.714224,-73.961452$

Output: Different Formatted Address

"formatted_address": "277 Bedford Avenue, Brooklyn, NY 1121, USA”,

"formatted_address": "Grand St/Bedford Av, Brooklyn, NY 11211, USA”,

"formatted_address": "Grand St/Bedford Av, Brooklyn, NY, 11249, USA”,

"formatted_address": "Bedford Av/Grand St, Brooklyn, NY 11211, USA",

\author{
"formatted_address": "Brooklyn, NY 11211, USA", \\ "formatted_address": "Williamsburg, Brooklyn, NY, \\ USA", \\ "formatted_address": "Brooklyn, NY, USA", \\ "formatted_address": "New York, NY, USA", \\ "formatted_address": "New York, USA", \\ "formatted_address": "United States",
}

For Little Botany, it is sufficient to use a simple address format, which consists of city and country.

5.3. Weather Services. Users can have their garden not only in different locations but also in different weather conditions. In Little Botany, users have an option to select historical time. For instance, users can have their garden in 2012. To retrieve weather condition for a specific location, we considered several weather provider sites [25]. In order to select a suitable weather provider site, we have considered API call limit, cost, and data provided by the site. As a result, we discovered that weather information can be retrieved over HTTP requests instead of calling their APIs and paying for services.

In the end, we selected Weather Underground [21] as the service that provides weather information to users. Weather Underground allows developers to query both current and historical weather data using HTTP links. Table 2 illustrates the retrieved weather data from wunderground.com on October 9, 2014, from 12:00 AM to 2:00 AM in Singapore airport. The link used for retrieving the data is

\section{https://www.wunderground.com/history/airport/SIN/ 2014/10/10/DailyHistory.html?format=1}

For Little Botany, we extract five attributes from Table 2 to describe weather condition for a specific location. The five attributes are time, temperature, humidity, events, and condition. 


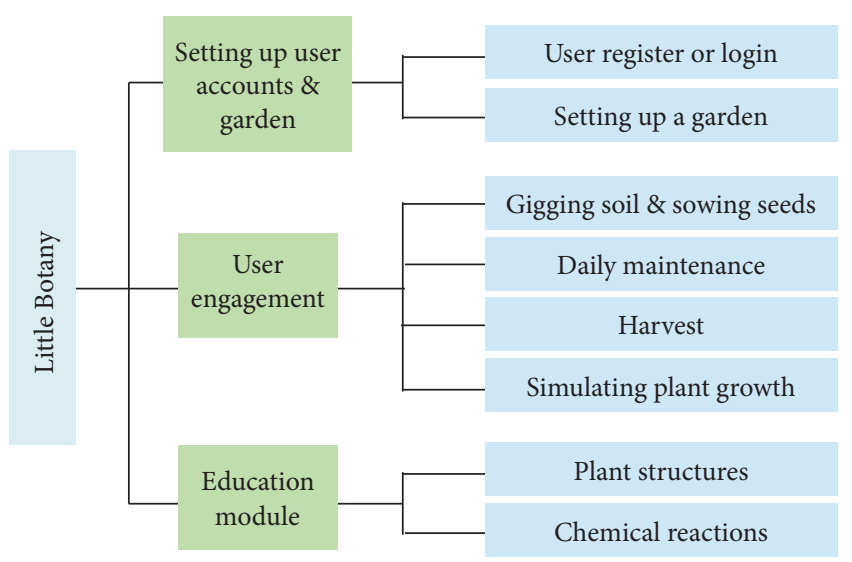

FIGURE 7: Little Botany's functionality diagram.

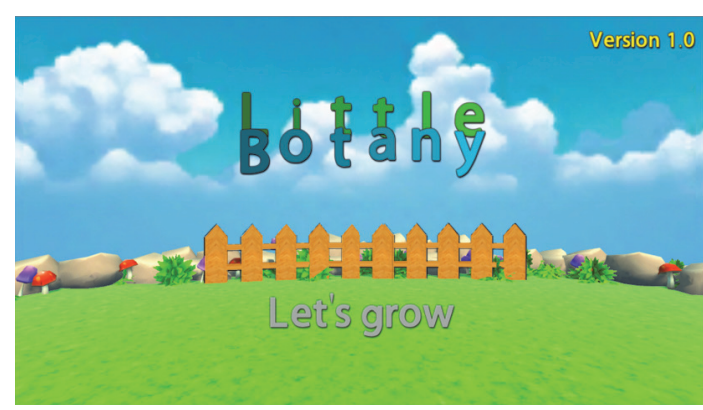

FiguRE 8: Start-game scene in Little Botany.

\section{Functionalities}

By playing with Little Botany, users can learn to grow and maintain their plants in different locations and weather conditions. Users can also track their plant growth. In addition, Little Botany provides an education module that teaches about in-depth gardening such as plant structure and factors affecting plant development. Figure 7 illustrates Little Botany functionalities diagram.

\subsection{Setting Up User Accounts and Garden}

6.1.1. User Register or Login. After a user installs Little Botany on a mobile device, he/she must create his/her account if he/she wants to start the game and create a garden. Figure 8 shows a snapshot of starting game scene in Little Botany. Players can click on the "Let's grow" button to start the game. After the game is started, the player can create his account by selecting the "Create new account" option or provide his username and password to login to the game, which are illustrated in Figure 9.

Little Botany authenticates username and password using Kii Cloud services. More importantly, Little Botany offers Single Sign-On feature with the support of Kii Cloud services, because Kii Cloud can automatically authenticate users by checking the current user's account or the user's session that appeared on the system.

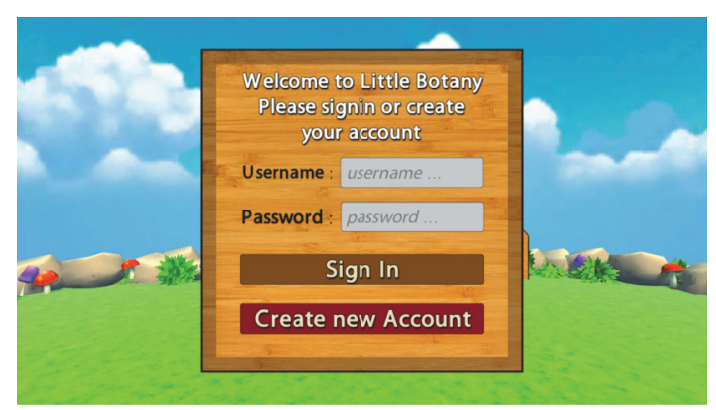

FIGURE 9: User login or register scene.

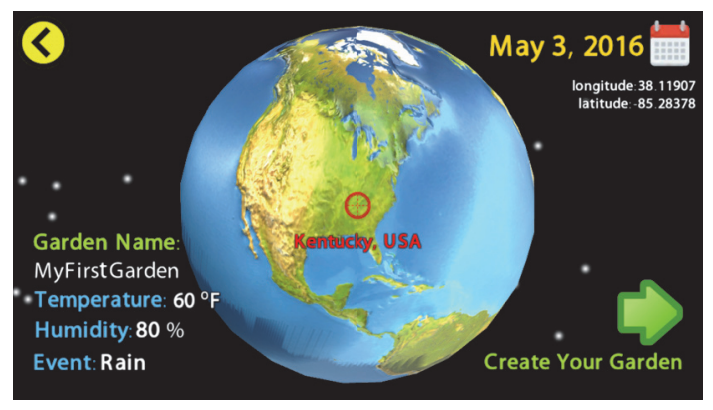

Figure 10: Select-location scene in Little Botany.

6.1.2. Setting Up a Garden. Users can create their dream gardens in different locations. Once users want to create their garden, Little Botany brings users to the location selection scene shown in Figure 10.

In Figure 10, users can select location by touching or clicking on the spherical globe. With the Unity3D game engine, we can retrieve user-touched position in 3-dimensional world and convert it to the geographical coordinates with latitude and longitude values. This technique can be achieved by using the formulas (see (1)) to convert Cartesian to spherical coordinates, where $r \in[0, \infty), \theta \in[0, \pi], \varphi \in[0,2 \pi)$, by

$$
\begin{aligned}
& r=\sqrt{x^{2}+y^{2}+z^{2}} \\
& \theta=\arccos \left(\frac{z}{\sqrt{x^{2}+y^{2}+z^{2}}}\right)=\arccos \left(\frac{z}{r}\right) \\
& \varphi=\arctan \left(\frac{y}{x}\right) .
\end{aligned}
$$

The Cartesian coordinate $(x, y, z)$ can be converted to spherical coordinate of a point in the ISO convention (radius $r$, inclination $\theta$, and azimuth $\varphi$ ). Azimuth angle $\varphi$ and inclination or polar angle $\theta$ are basically the same as latitude and longitude values.

The latitude and longitude values are used to retrieve both weather information and location information. In addition, we also provide calendar for our users to select a specific day for starting a garden. After users have selected their location and a date from the calendar, our game will bring users to 


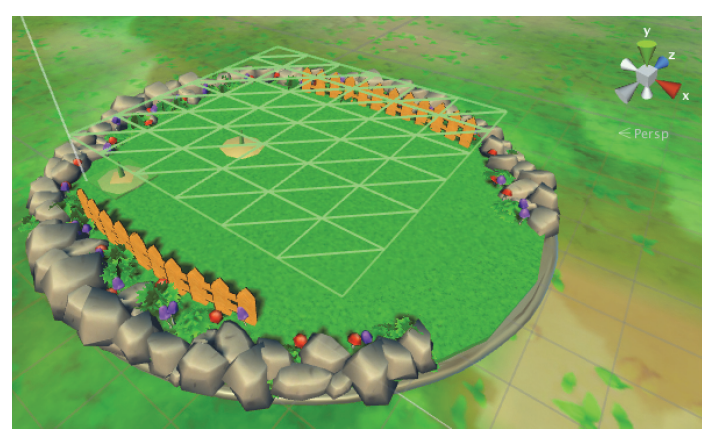

FIGURE 11: Little Botany garden with tile map structure.

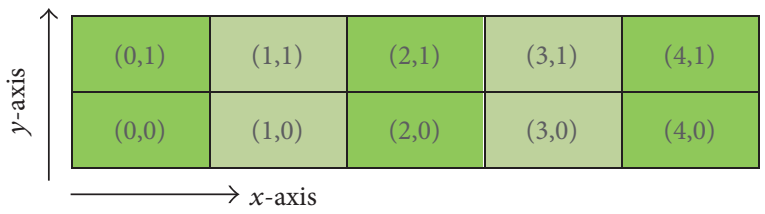

Figure 12: $(5 \times 2)$ tile map structure.

their garden. Users are able to grow plants and vegetables by selecting a specific tile in this scene. We have designed user's garden using 2-dimensional tile map as shown in Figure 11. The tile map is structured in $(x, y)$ axis. Figure 12 shows how Little Botany stores positions in the tile map system.

Users start growing their plants and vegetables by selecting gardening tools. After sowing the tomato seed to the soil, users can track the tomato plant's development and user's activity logs and learn about the structure of tomato plant. Little Botany displays a detailed description for each plant, which includes health condition, water amount, plant state, and plant type.

6.2. User Engagement. In Little Botany, we provide five gardening tools, shovel, seed can, water pitcher, pesticide spray, and scissor, which are shown at the bottom of the snapshot in Figure 13. The gardening tools are important components for plant maintenance. We describe the roles and functionalities of each tool with snapshots as follows:

(a) Shovel: to use a shovel for digging soil, users can interact with the game by swiping their fingers. Each swipe will play the digging animation and is being counted

(b) Seed can: users can select a specific seed from Little Botany's seed store and start sowing the seed by holding the button until the progress bar has filled

(c) Watering: users hold on the watering button until watering gauge reaches the required amount. In some cases, plant will display a message if it still needs more water

(d) Pesticide spray: users can interact with the game by destroying harmful insects. Users can spray pesticide

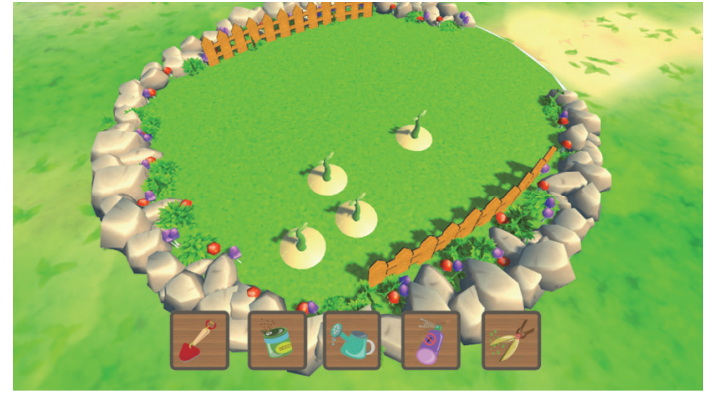

Figure 13: Gardening tools.

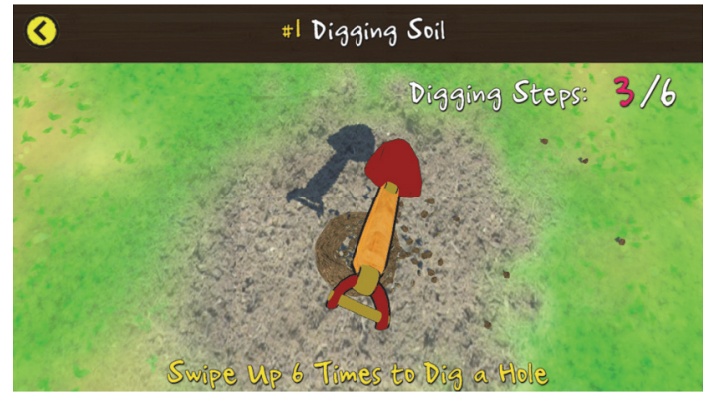

Figure 14: Digging-soil scene.

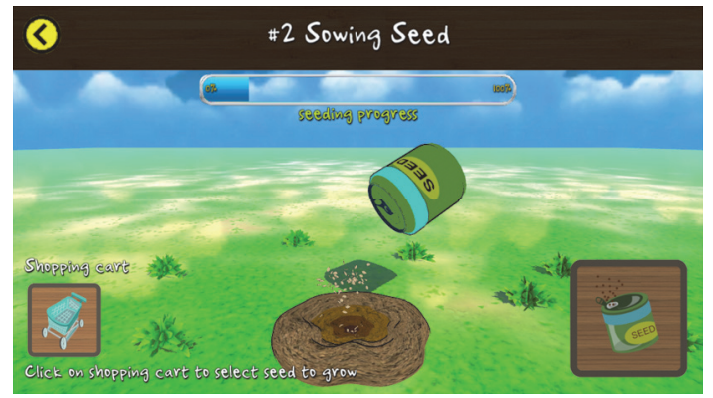

FIGURE 15: Sowing-seed scene.

to the insect, and the insect will be eliminated from the plant

(e) Scissor: users use a scissor to harvest the fruit from a plant. Users pick a specific fruit and put it into a basket. Users will earn money by selling those fruits they picked.

(1) Digging Soil and Sowing Seeds. Users will start digging the soil by performing the swipe gesture; after that, users will start sowing plant seeds by selecting their favorite plant they would like to grow. Figures 14 and 15 show a snapshot of digging soil and sowing seeds in Little Botany, respectively.

In beta version of Little Botany, we provide three vegetables: tomatoes, carrots, and onions. We plan to provide twenty common plants and vegetables in the near future. The list of 


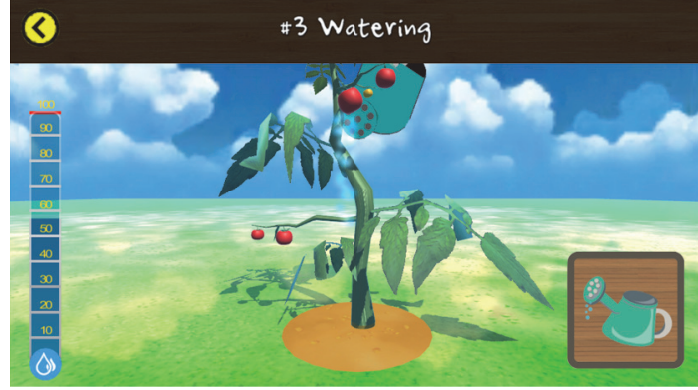

FIGURE 16: Watering scene.

most common plants and vegetables that users can grow on Little Botany in the near future is as follows:

Apples
Onions
Potato
Spinach
Peaches
Tomatoes
Asparagus
Blueberries
Grapes
Lettuce
Celery
Avocado
Egg plant
Watermelon
Peppers
Strawberries
Cabbage
Kale
Kiwi
Pine apple

(2) Garden Daily Maintenance. Little Botany requires users to water and spray pesticide to their plants and vegetables. Tomatoes are susceptible to insect pests, especially tomato hornworms and whiteflies. Users should maintain their plants on a daily basis. Figures 16 and 17 show a snapshot of watering tomato and spraying pesticide, respectively. If some weather events have occurred, the maintenance activities will be adjusted accordingly. For example, if it rains on a specific day, users do not need water plants in their gardens.

(3) Harvest. When a plant reaches its final growing season, users can harvest the vegetable or fruit from the plant. Figure 18 shows a snapshot of harvesting tomato. Harvest time for tomatoes will occur at the end of its growing season, once the tomatoes are at their mature green stage. Users will

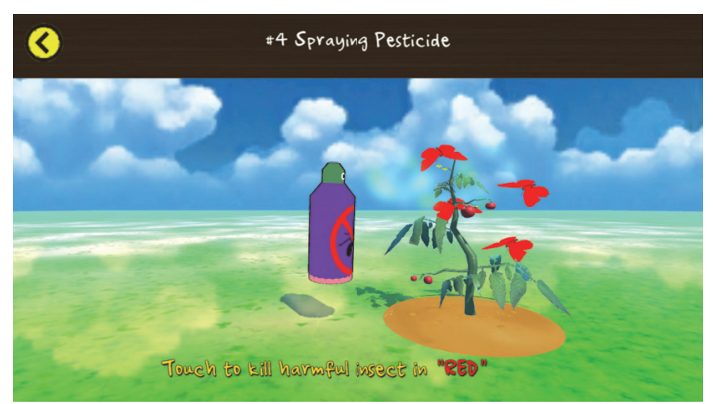

FIGURE 17: Spraying-pesticide scene.

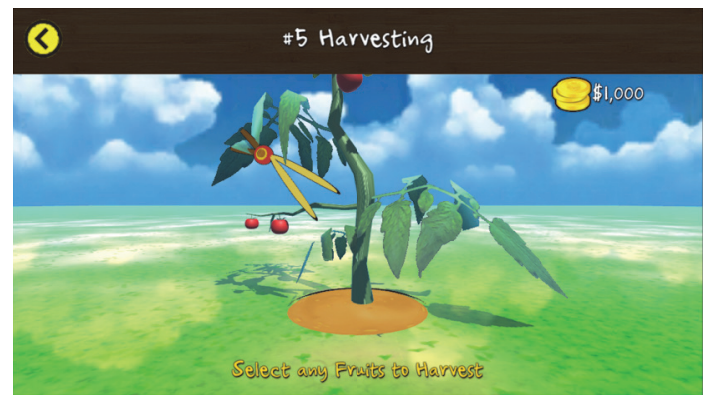

FIGURE 18: Harvesting scene.

start picking about $60-85$ days after planting seedlings in the garden.

Playing with Little Botany, users can learn how to grow their plants and vegetables. Moreover, users can learn to take care of their garden in different seasons and locations. After harvest, users can sell the fruit for money and then buy seeds for a new plant.

(4) Simulating Plant Growth. The principal environmental requirements for plant growth include adequate space for root and canopy development, sufficient light, water, oxygen, carbon dioxide, and mineral elements, and temperature suitable for essential physiological processes. An adequate amount of water is essential for plant growth. To simulate plant growth and development, we use Growing Degree-Day (GDD) formula (see (2)) to calculate a plant's development rate based upon real-time weather data. For tomato plant, GDD formula is defined as follows:

$$
\mathrm{GDD}=\frac{T_{\max }+T_{\min }}{2}-T_{\text {base }}
$$

$T_{\max }$ is maximum temperature, $T_{\min }$ is minimum temperature, and $T_{\text {base }}$ is usually equal to $50^{\circ} \mathrm{F}$.

Each plant in the garden has a timestamp, which records the plant's starting date. The game automatically calculates how long the plant has been growing based upon the timestamp. Then the game calculates the amount of water that each plant requires so that users can provide an adequate growing environment for the plant. Table 3 shows water amount based upon tomato stages and weather conditions. 
TABLE 3: Water amount based upon tomato stages and weather conditions.

\begin{tabular}{|c|c|c|c|c|c|c|c|c|}
\hline \multirow{3}{*}{$\begin{array}{l}\text { Tomato plant } \\
\text { stage }\end{array}$} & \multirow{3}{*}{$\begin{array}{c}\text { Stage } \\
\text { description }\end{array}$} & \multirow{3}{*}{$\begin{array}{c}\text { Days of } \\
\text { development }\end{array}$} & \multicolumn{6}{|c|}{ Weather condition $(\mathrm{mm}=$ millimeters $)$} \\
\hline & & & \multicolumn{3}{|c|}{ Day time } & \multicolumn{3}{|c|}{ Night time } \\
\hline & & & Clear & Cloudy & Rain, snow, thunder & Clear & Cloudy & Rain, snow, thunder \\
\hline 1 & Establishment & $1-3$ days & 7 & 6 & 0 & 5 & 4 & 0 \\
\hline 2 & Establishment & $3-5$ days & 12 & 11 & 0 & 10 & 9 & 0 \\
\hline 3 & Establishment & 5-7 days & 17 & 16 & 0 & 15 & 14 & 0 \\
\hline 4 & $\begin{array}{c}\text { Development } \\
\text { and vegetable } \\
\text { growth }\end{array}$ & 7-10 days & 22 & 21 & 0 & 20 & 19 & 0 \\
\hline 5 & $\begin{array}{c}\text { Development } \\
\text { and vegetable } \\
\text { growth }\end{array}$ & 10-14 days & 27 & 26 & 0 & 25 & 24 & 0 \\
\hline 6 & $\begin{array}{l}\text { Fruit flowering } \\
\text { and fruit set }\end{array}$ & 14-28 days & 32 & 31 & 0 & 30 & 29 & 0 \\
\hline 7 & $\begin{array}{c}\text { Fruit flowering } \\
\text { and fruit set }\end{array}$ & 28-35 days & 37 & 36 & 0 & 35 & 34 & 0 \\
\hline 8 & $\begin{array}{l}\text { First phase of } \\
\text { fruit } \\
\text { development }\end{array}$ & $35-40$ days & 42 & 41 & 0 & 40 & 39 & 0 \\
\hline 9 & $\begin{array}{l}\text { Harvest } \\
\text { initiation }\end{array}$ & 40-45 days & 47 & 46 & 0 & 45 & 44 & 0 \\
\hline 10 & Full harvest & 45-60 days & 52 & 51 & 0 & 50 & 49 & 0 \\
\hline
\end{tabular}

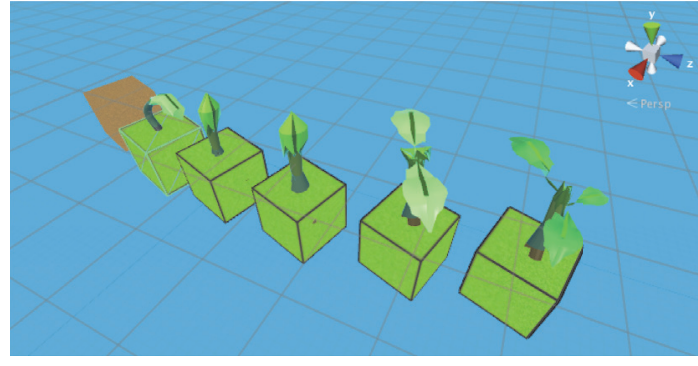

FIGURE 19: Five development stages of tomatoes.

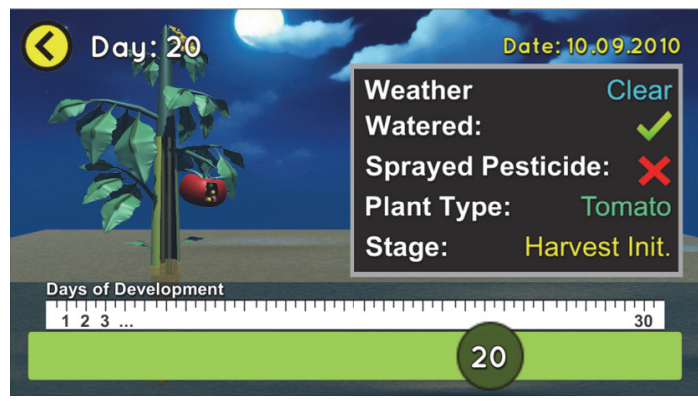

FIgURE 20: Tracking plant scene.

Figure 19 illustrates five models of tomatoes, each model represented as one development stage.

(5) Tracking Plant Growth. Users should perform daily activities to take care of the plants in their garden. Activities such as watering and spraying pesticide will be stored in the activity

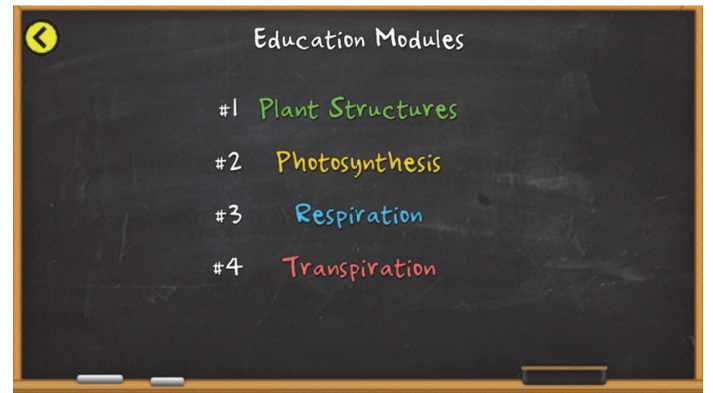

FIGURE 21: Content of education modules scene.

log. Users can keep track of all plant development since the first day the plant has been planted. In order to track a specific plant, Little Botany uses the scroll bar. For example, a user started growing his tomato on January 11, 2010. When the user logs in Little Botany on January 15, 2010, he can drag the scroll bar within five days, view his daily activities, and check plant's status. Figure 20 shows a snapshot of the trackingplant-growth scene.

Little Botany uses activity logs to keep track of users' activities and plant's development. Activity data including watering, spraying pesticides, and plant health data is recorded in the activity logs. Therefore, when a user drags the scroll bar, Little Botany displays all the activities the user has performed in his garden.

6.3. Education Module. In addition to tracking plants' development, Little Botany can also teach users about plant structure, photosynthesis, respiration, and transpiration, which are listed in Figure 21. Plant structure is divided into two 


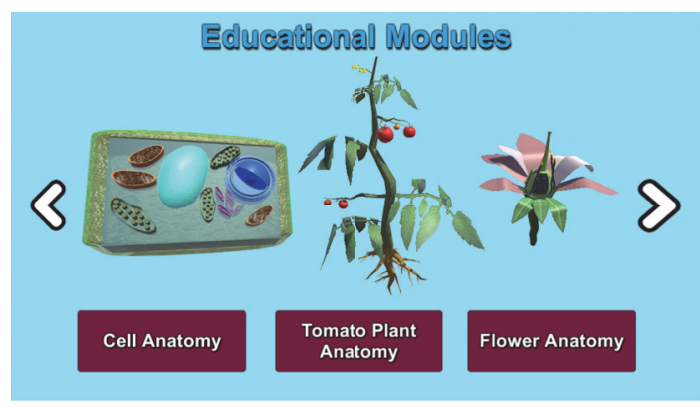

Figure 22: Plant structures-selection scene.

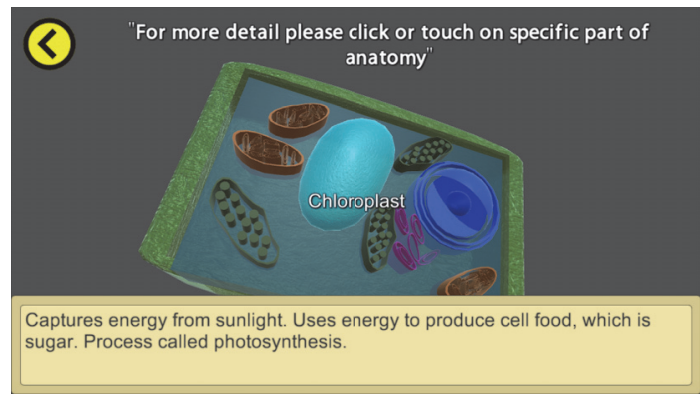

FIgURE 23: Cell-anatomy scene.

parts: external structure and internal structure. External parts consist of root, stem, leaf, flower, fruit, and seed. Internal parts consist of plant cell and plant tissue. When a user touches on a specific part of the plant, a detailed description of the functions for the touched part will be displayed to the user.

Using tomato plant as an example, Figure 22 illustrates the plant-structures-selection scene where users can select different topics such as plant cell anatomy, tomato plant anatomy, and flower structures. Figure 23 shows a snapshot of cell anatomy scene. This scene provides a free rotation of objects. Thus, users can interact with the plant in a 360degree view. Moreover, users can learn a specific part of anatomy by touching on an individual part. Figure 24 shows a snapshot of respiration scene; Figure 25 shows a snapshot of photosynthesis scene; and Figure 26 shows a snapshot of transpiration scene.

\section{Evaluation}

The primary characteristics of a mobile game which make it enjoyable are its content, storyboard, rewards, graphics, sound effects, and user experience. Korhonen and Koivisto [26] have defined heuristics termed as playability heuristics to evaluate mobile games. These heuristics are divided into three modules: game usability, mobility, and gameplay. The game usability module covers the game controls and interface through which the player interacts with the game. Also, it contains common usability aspects that help the player to get into the game and interact with it. Mobility module deals with the characteristics of mobile devices and their context

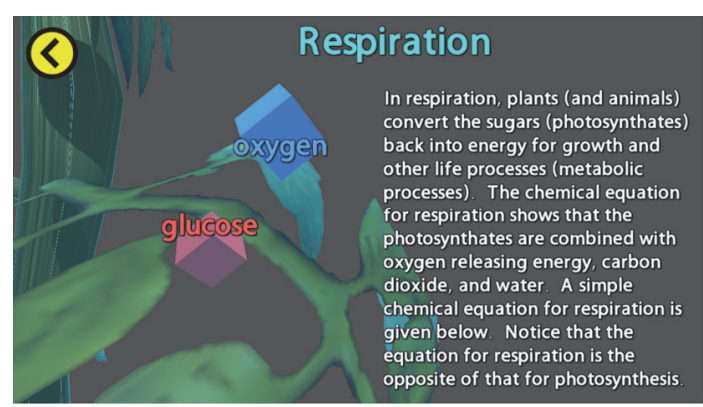

FIgURE 24: Respiration scene.

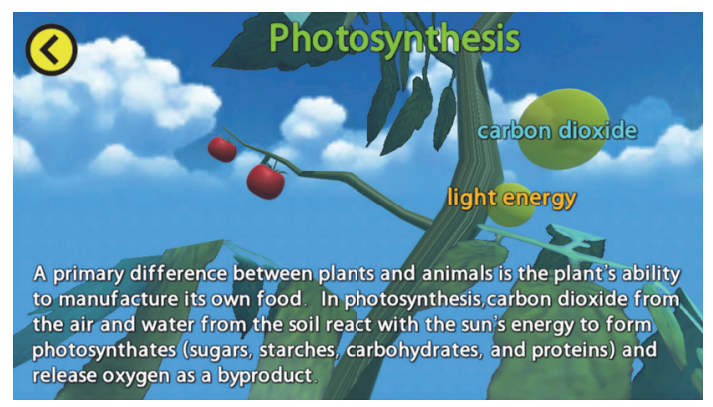

Figure 25: Photosynthesis scene.

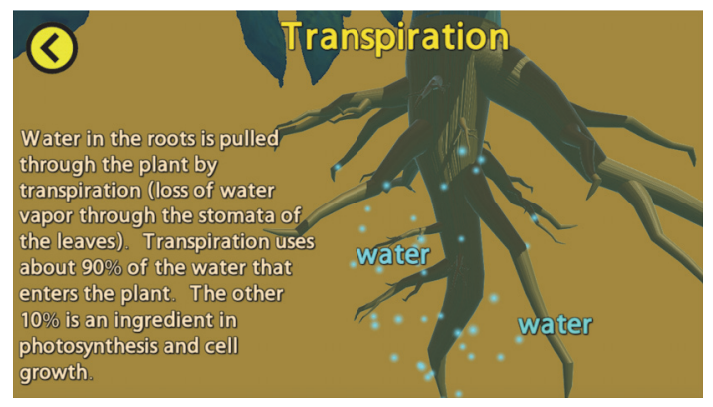

Figure 26: Transpiration scene.

that can influence the design of games. The gameplay module deals with issues that arise when the player interacts with the game's mechanics and story. The playability heuristics discussed by Korhonen and Koivisto [26] were summarized in Tables 4, 5, and 6 .

7.1. User Study Design. In our design and evaluation, our main priority has been usability and playability rather than a dense educational content. Assessing playability and usability in such a game is essential as it will determine if and for how long the children will be using it, which is an important factor for ensuring learning success.

A total of 28 school-aged children including 12 females and 16 males were purposely recruited from Sunday school at The Chapel in Akron. Participants were asked to have experience of using mobile devices (including smartphones and tablets). We manually installed the game on either 
TABLE 4: Heuristics for evaluating game usability.

\begin{tabular}{ll}
\hline$\#$ & Game usability heuristics \\
\hline 1 & Audiovisual representation supports the game \\
2 & Screen layout is efficient and visually pleasing \\
3 & Device UI and game UI are used for their own purposes \\
4 & Indicators are visible \\
5 & The player understands the terminology \\
6 & Navigation is consistent, logical, and minimalist \\
7 & Control keys are consistent and follow standard conventions \\
8 & Game controls are convenient and flexible \\
9 & The game gives feedback on the player's actions \\
10 & The player cannot make irreversible errors \\
11 & The player does not have to memorize things unnecessarily \\
12 & The game contains help \\
\hline
\end{tabular}

TABLE 5: Heuristics for evaluating mobility.

\begin{tabular}{ll}
\hline$\#$ & Mobility heuristics \\
\hline 1 & The game and play sessions can be started quickly \\
2 & The game accommodates with the surroundings \\
3 & Interruptions are handled reasonably \\
\hline
\end{tabular}

TABLE 6: Heuristics for evaluating gameplay.

\begin{tabular}{ll}
\hline$\#$ & Gameplay heuristics \\
\hline 1 & $\begin{array}{l}\text { The game provides clear goals or supports player created } \\
\text { goals }\end{array}$ \\
2 & $\begin{array}{l}\text { The player sees the progress in the game and can compare the } \\
\text { results }\end{array}$ \\
3 & The players are rewarded and rewards are meaningful \\
4 & The player is in control \\
5 & Challenge, strategy, and pace are in balance \\
6 & The first-time experience is encouraging \\
7 & The game story supports the gameplay and is meaningful \\
8 & There are no repetitive or boring tasks \\
9 & The players can express themselves \\
10 & The game supports different playing styles \\
11 & The game does not stagnate \\
12 & The game is consistent \\
13 & The game uses orthogonal unit differentiation \\
14 & The player does not lose any hard-won possessions \\
\hline
\end{tabular}

participant's or their parent's mobile devices. 18 participants play the game on tablets, and 10 participants play the game on smartphones. We had a quick presentation session to teach participants how to play the game. We asked participants to play Little Botany for a period of three weeks. During this time, players were asked to play with Little Botany at least 3 times a week. After playing the game for three weeks, participants were asked to complete questionnaires regarding usability and playability. The questionnaire we used in our user study is adapted from the playability heuristics proposed
TABLE 7: The statements used in questionnaire to evaluate usability.

\begin{tabular}{ll}
\hline$\# \quad$ Statements \\
\hline $\mathrm{Q}_{1}$ & Screen layout is efficient and visually pleasing. \\
$\mathrm{Q}_{2}$ & The symbols and words on screen were easy to understand. \\
$\mathrm{Q}_{3}$ & The amount of information displayed on screen was \\
$\mathrm{Q}_{4}$ & The information displayed on screen was consistent. \\
$\mathrm{Q}_{5}$ & Navigation is consistent and logical. \\
$\mathrm{Q}_{6}$ & The game and play sessions can be started quickly. \\
$\mathrm{Q}_{7}$ & Game controls are convenient and flexible. \\
$\mathrm{Q}_{8}$ & The game gives feedback on the player's actions. \\
$\mathrm{Q}_{9}$ & The player does not have to memorize things unnecessarily. \\
$\mathrm{Q}_{10}$ & The help contained in the game is useful. \\
\hline
\end{tabular}

TABLE 8: The statements used in questionnaire to evaluate playability.

\begin{tabular}{ll}
\hline$\#$ & Statements \\
\hline $\mathrm{Q}_{1}$ & The first-time experience is encouraging. \\
$\mathrm{Q}_{2}$ & The game provides clear goals. \\
$\mathrm{Q}_{3}$ & The player sees the progress in the game. \\
$\mathrm{Q}_{4}$ & The player is rewarded and rewards are meaningful. \\
$\mathrm{Q}_{5}$ & The player feels that challenge and pace are in balance. \\
$\mathrm{Q}_{6}$ & The game story supports the gameplay and is meaningful. \\
$\mathrm{Q}_{7}$ & There are no repetitive or boring tasks. \\
$\mathrm{Q}_{8}$ & The game does not stagnate. \\
$\mathrm{Q}_{9}$ & The player improved his/her knowledge about gardening. \\
$\mathrm{Q}_{10}$ & The player became more interested in real-world gardening. \\
\hline
\end{tabular}

by Korhonen and Koivisto [26]. The ten statements used to measure game's usability and playability are listed in Tables 7 and 8 , respectively.

7.2. Results. Participants were asked to answer to what extent they agree to the statements in Tables 7 and 8. We use a 5point Likert scale ranging from strongly disagree to strongly agree. The results of experiments evaluating usability are shown in Figure 27.

We were interested to know if players find the game's controls and interface pleasing. We were also interested to know if the players think the content, graphics, and sound effects are enjoyable. As shown in Figure 27, Little Botany shows a high level of usability according to the responses of participants (the average score is greater than 3.9 for all parameters). To really give a game player what he/she wants, we have to understand what is important to him/her: we have to care about what he/she cares about and think how he/she thinks. One of the main challenges with Little Botany is to provide players with experience that they feel the existence of virtual gardens in the real world. Participants reported that they felt they were maintaining a real garden in Little Botany.

The results of experiments evaluating playability are shown in Figure 28. 


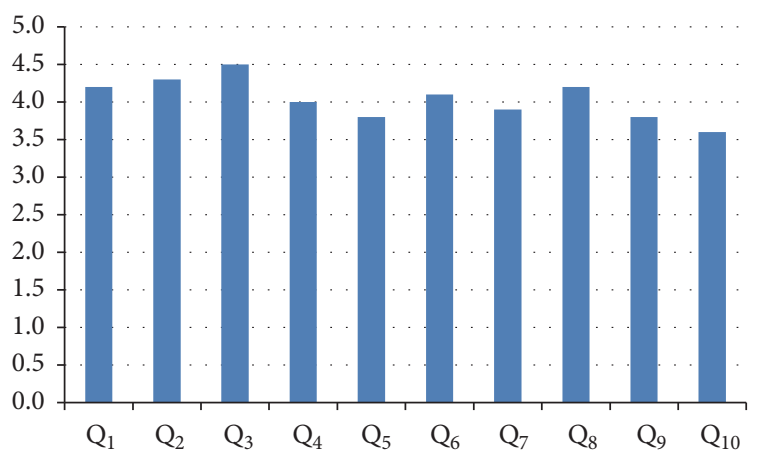

FIGURE 27: The average score of statements in Table 7 answered by participants to measure usability.

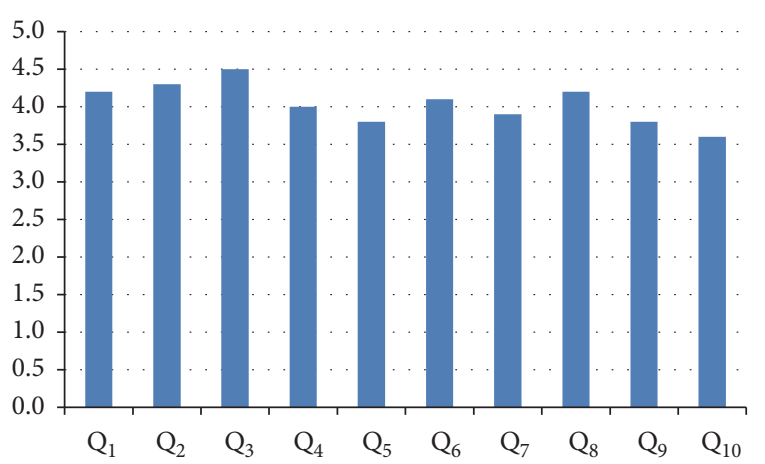

FIGURE 28: The average score of statements in Table 8 answered by participants to measure playability.

We were interested to know if players think the storyboard and user experience are enjoyable. We were also interested to know if the game improved the players' knowledge about gardening. As shown in Figure 28, Little Botany shows a high level of playability according to the responses of participants (the average score is greater than 4.0 for all parameters). Although the overall score is acceptable, the average scores for $\mathrm{Q}_{9}$ (the player improved his/her knowledge about gardening) and $\mathrm{Q}_{10}$ (the player became more interested in real-world gardening) are somehow low in comparison to other questions. We argue that three weeks is not long enough to measure the educational effectiveness of our game. Therefore, we plan to perform additional long-term experiments to measure the educational effectiveness of Little Botany.

\section{Conclusion}

Games are important for learning development. In this paper, we present a mobile educational game for gardening to enhance plant science learning and improve student content retention. Using Little Botany, users can create their dream garden in any place in the world. More importantly, Little Botany is using real-time weather data for the garden location (e.g., South America) to simulate how the weather affects plants growth. Weather plays a major role in the healthy growth and development of plants. To engage users, Little Botany has plant daily maintenance component which requires users' daily involvement with the game. With this game, users can discover where our food comes from and learn how to tend and harvest crops and learn about insects and pollinators. The current virtual garden in Little Botany is simulated based upon soil gardening, but we plan to add indoor hydroponic system to our game in the near future. Hydroponic gardening [27] uses considerably less water than soil gardening because of the constant reuse of the nutrient solutions. Mobile devices are rapidly becoming the new medium of educational and social life for young people, and hence mobile educational games are a key topic for learning.

\section{Conflicts of Interest}

The authors declare that they have no competing interests.

\section{References}

[1] J. Paul Gee, What Video Games Have to Teach Us about Learning and Literacy, vol. 1 of Theoretical and Practical Computer Applications in Entertainment, 2003.

[2] T. M. Connolly, E. A. Boyle, E. MacArthur, T. Hainey, and J. M. Boyle, "A systematic literature review of empirical evidence on computer games and serious games," Computers and Education, vol. 59, no. 2, pp. 661-686, 2012.

[3] M. Virvou and E. Alepis, "Mobile educational features in authoring tools for personalised tutoring," Computers and Education, vol. 44, no. 1, pp. 53-68, 2005.

[4] F. Ke, "A case study of computer gaming for math: engaged learning from gameplay?" Computers and Education, vol. 51, no. 4, pp. 1609-1620, 2008.

[5] I. Boada, A. Rodriguez-Benitez, J. M. Garcia-Gonzalez, S. Thió-Henestrosa, and M. Sbert, "30: 2: a game designed to promote the cardiopulmonary resuscitation protocol," International Journal of Computer Games Technology, vol. 2016, Article ID 8251461, 14 pages, 2016.

[6] J. P. Gee, "Learning by design: good video games as learning machines," E-Learning, vol. 2, no. 1, pp. 5-16, 2005.

[7] H. J. Hsu, "The potential of kinect in education," International Journal of Information and Education Technology, vol. 1, no. 5, pp. 365-370, 2011.

[8] S. Jamonnak and E. Cheng, "Little botany: a mobile educational game for gardening," in Proceedings of the 15th International Conference on e-Learning, e-Business, Enterprise Information Systems, and e-Government (EEE '16), Las Vegas, Nev, USA, 2016.

[9] N. Castilla and J. Lopez-Galvez, "Vegetable crop responses in improved low-cost plastic greenhouses," Journal of Horticultural Science, vol. 69, no. 5, pp. 915-921, 1994.

[10] TeamLava Games, “Google play store: Farm story," https://play .google.com/store/apps/details?id=com.teamlava.farmstory.

[11] Google play store: inner garden, https://play.google.com/store/ apps/details?id=com.dustflake.innergarden.

[12] Gameinsight, "Google play store: flower house," 2016, https:// play.google.com/store/apps/details?id=com.gameinsight.flowerhouseandroid.

[13] SPRING GAMES, “Google play store: sweet garden,” 2016, https:// play.google.com/store/apps/details?id=toast.sweetgarden. 
[14] TutoTOONS Kids Games, "Google play store: dream garden," https://play.google.com/store/apps/details?id=air.com.tutotoons .app.dreamgarden.

[15] P. Rooney, "A theoretical framework for serious game design: exploring pedagogy, play and fidelity and their implications for the design process," International Journal of Game-Based Learning, vol. 2, no. 4, pp. 41-60, 2012.

[16] L. A. Annetta, "The 'I's' have it: a framework for serious educational game design," Review of General Psychology, vol. 14, no. 2, pp. 105-112, 2010.

[17] M. De Sá and L. Carriço, "Designing and evaluating mobile interaction: challenges and trends," Foundations and Trends in Human-Computer Interaction, vol. 4, no. 3, pp. 175-243, 2010.

[18] “Unity3D Game Engine," https://unity3d.com/.

[19] Autodesk Maya, http://www.autodesk.com/products/maya/overview-dts?s_tnt=69290:1:0.

[20] "Kii Cloud," https://en.kii.com/.

[21] "Weather Underground API," http://www.wunderground.com/.

[22] Google Geocode API, https://developers.google.com/maps/ documentation/geocoding/intro.

[23] Mobile Backend as a Service (MbaaS), https://en.wikipedia.org/ wiki/Mobile_backend_as_a_service.

[24] Best MbaaS, http://forum.unity3d.com/threads/best-mbaassolutions.252863/.

[25] Top 10 Weather API, http://www.programmableweb.com/ news/top-10-weather-apis/analysis/2014/11/13.

[26] H. Korhonen and E. M. I. Koivisto, "Playability heuristics for mobile games," in Proceedings of the 8th International Conference on Human-Computer Interaction with Mobile Devices and Services (MobileHCI '06), pp. 9-16, Helsinki, Finland, September 2006.

[27] M. H. Jensen and W. L. Collins, "Hydroponic vegetable production," in Horticultural Reviews, J. Janick, Ed., vol. 7, John Wiley \& Sons, Hoboken, NJ, USA, 1985. 


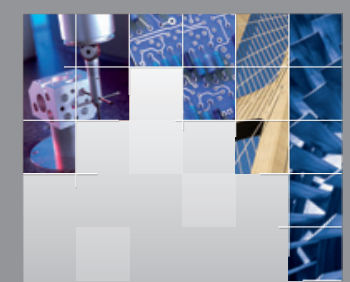

\section{Enfincering}
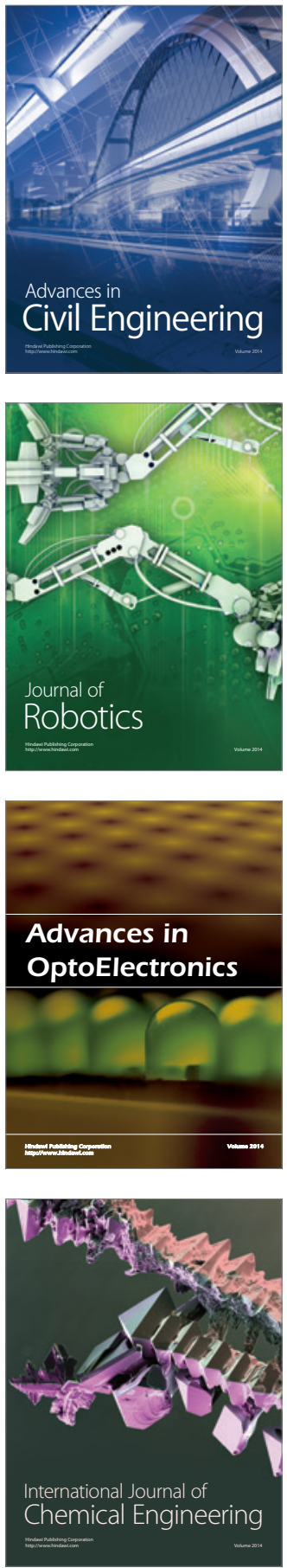

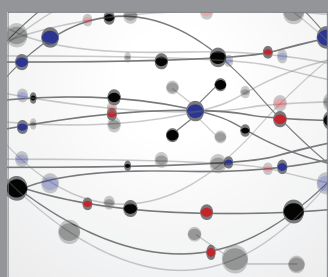

The Scientific World Journal

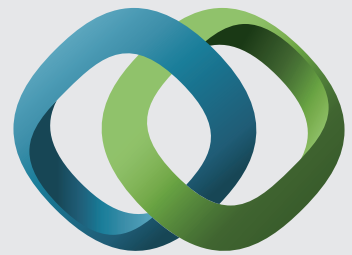

\section{Hindawi}

Submit your manuscripts at

https://www.hindawi.com
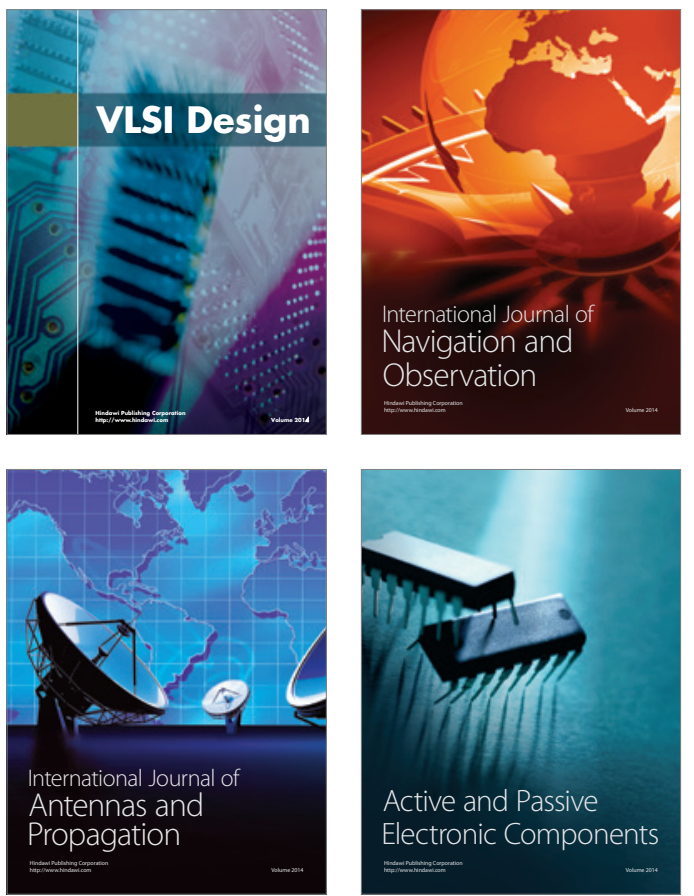
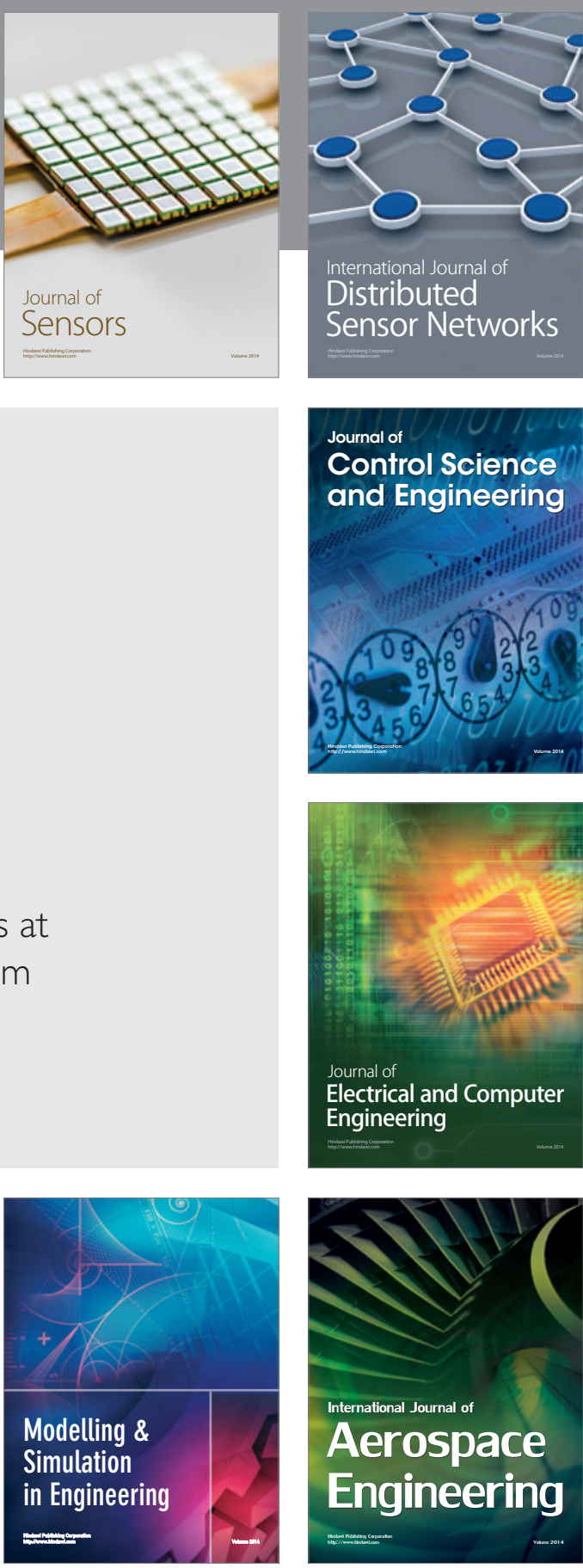

International Journal of

Distributed

Sensor Networks

$-$

Joumal of

Control Science

and Engineering
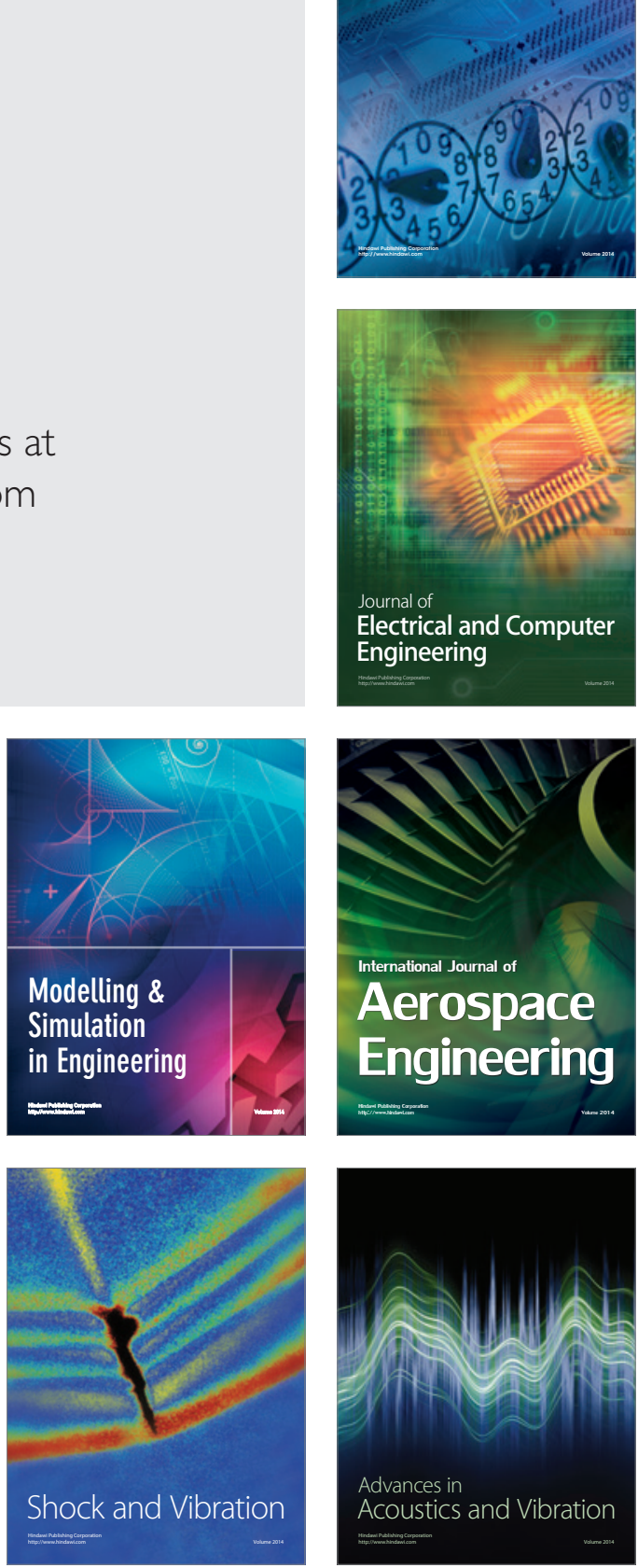